\title{
Adeno associated viral vector-delivered and hypoxia response element-regulated CD151 expression in ischemic rat heart
}

\author{
Quan WEI, Xiao-lin HUANG* ${ }^{*}$, Jing-yang LIN*, Yu-jie FEl, Zheng-xiang LIU*, Xin A ZHANG ${ }^{\S}$ \\ Department of Rehabilitation Medicine of Tongji Hospital, Tongji Medical College, Huazhong University of Science and Technology, \\ Wuhan 430030, China
}

\begin{abstract}
Aim: The aim of this study was to improve the delivery efficacy and target specificity of the pro-angiogenic gene CD151 to the ischemic heart.

Methods: To achieve the inducible expression of adeno-associated viral (AAV)-delivered CD151 gene in only the ischemic myocardium, we generated an AAV construct in which CD151 expression can be controlled by the hypoxia response element (HRE) sequence from the human Enolase gene. The function of this vector was examined in rat $\mathrm{H} 9 \mathrm{C} 2$ cardiac myoblasts and in ischemic rat myocardium. The expression of CD151 in the areas of ischemic myocardium was confirmed at the mRNA level by real-time PCR and on the protein level by Western blot, whereas the CD151 expression in the microvessels within the areas of ischemic myocardium was detected by immunohistochemistry.

Results: HRE significantly enhances the expression of CD151 under hypoxic conditions or in the ischemic myocardium, and forced CD151 expression increases the number of microvessels in the ischemic myocardium.

Conclusion: The AAV-mediated, HRE regulated delivery of the CD151 gene shows higher expression in the ischemic myocardium and more efficiently targets CD151 to the hypoxic regions after myocardial infarction.
\end{abstract}

Keywords: cardiac ischemia; CD151; angiogenesis; gene therapy; gene expression; hypoxia response element

Acta Pharmacologica Sinica (2011) 32: 201-208; doi: 10.1038/aps.2010.205; published online 17 Jan 2011

\section{Introduction}

The transfer of angiogenic genes to the ischemic myocardium likely provides a useful approach for the treatment of coronary artery disease ${ }^{[1]}$. The CD151 protein is a member of the tetraspanin superfamily and contains four hydrophobic transmembrane domains, two extracellular loops, and two short cytoplasmic tails ${ }^{[2,3]}$. Tetraspanins associate both with each other and with other integral membrane proteins, including integrins and members of the immunoglobulin superfamily ${ }^{[4,5]}$. CD151 is expressed in various cell types, including epidermal basal cells, smooth cells, skeletal cells, cardiac muscle cells, endothelial cells, epithelial cells, platelets, and Schwann cells; it is also characteristically localized in intracellular vesicles

\footnotetext{
"Now in Department of Cardiology of Zhejiang Provincial People's Hospital, Hangzhou 310014, China.

${ }^{\S}$ Now in Vascular Biology and Cancer Centers, University of Tennessee Health Science Center, Memphis, Tennessee, USA.

* To whom correspondence should be addressed.

E-mail liuzhengxiang@hotmail.com (Zheng-xiang LIU); xiaolinh2006@yahoo.com.cn (Xiao-lin HUANG)

Received 2010-09-02 Accepted 2010-11-02
}

and cell adhesion structures ${ }^{[4,6]}$. Our previous studies have shown that the direct injection of an AAV vector carrying the CD151 gene to the ischemic rat myocardium induces neovasculature formation, and the CD151 gene delivery increases the number of microvessels in an ischemic rat hind limb model ${ }^{[7,8]}$. Further studies with a swine myocardial infarction model indicated that CD151 gene delivery induces both angiogenesis and arteriogenesis by increasing the capillary and arteriole density $^{[9,10]}$. These observations strongly suggest that CD151 can be used for gene therapy with myocardial ischemia by promoting angiogenesis.

With the continued progress of gene therapy, there have been more concerns regarding the safety of gene therapy and the routes of gene delivery. The current routes of gene delivery to the heart include direct myocardial, trans-catheter myocardial, coronary artery, and intravenous injections. Intravenous injection is a non-invasive, safe gene-import method; however, it is not possible to introduce high concentrations of exogenous genes into the ischemic myocardium to induce sufficient angiogenesis using this method. If high doses of exogenous genes are administered, there would be an increase 
in the exposure of the gene to the normoxic myocardium as well as other organs and also an increase in the potential side effects in non-ischemic sites such as hemangioma formation and retinopathy ${ }^{[11,12]}$. Although such complications were not observed in our previous animal studies on CD151, it is crucial to minimize these complications for the upcoming clinical applications of CD151. Thus, for intravenous administration, it is of immediate concern to find a method that will increase CD151 expression specifically in the ischemia myocardium but not in the normoxic myocardium and other organs.

For the treatment of ischemic heart disease, an ideal control for CD151 gene expression seems to be the response to hypoxia; that is, there is high expression of the CD151 gene in the ischemic areas and low expression in the non-ischemia areas. Hypoxia-inducible factor-1 (HIF-1) is induced or upregulated under conditions of hypoxia and regulates gene expression by binding to a cis-acting hypoxia-responsive element (HRE) $)^{[13,14]}$. The HRE has been found in human enolase $(\mathrm{ENO})^{[15]}$, erythropoietin (Epo $)^{[16]}$, and several other genes. The core consensus sequence is $(\mathrm{A} / \mathrm{G}) \mathrm{CGT}(\mathrm{G} / \mathrm{C}) \mathrm{C}$. HRE sequences of ENO and Epo have been used to regulate the expression of genes such as vascular endothelial growth factor $(\mathrm{VEGF})^{[14]}$ and suicide ${ }^{[17]}$ or apoptosis ${ }^{[18]}$ genes.

In this study, we use the AAV-HRE-CD151 vector, which carries one copy of the HRE from ENO, to determine the applicability and feasibility of the hypoxia-induced, HREdriven expression of CD151 in the ischemic myocardium. Our study demonstrated that the ENO HRE can induce CD151 expression under hypoxic conditions in both cultured cardiomyocytes in vitro and ischemic rat myocardium in vivo.

\section{Materials and methods}

\section{Vector construction and production}

The AAV constructs carrying human CD151 or green fluorescent protein (GFP) cDNA were generated as described previously ${ }^{[7,19]}$. Based on the previous study by Philips et a ${ }^{[20]}$, a 68-bp HRE sequence from the human Enolase 1 gene was inserted into the pAAV-CD151 construct between the MluI and BamHI restriction sites upstream of the cytomegalovirus promotor to generate the pAAV-HRE-CD151 construct.

\section{Cell culture and transfection}

Rat cardiac myoblasts (H9C2) were obtained from American Type Culture Collection, cultured in Dulbecco's modified Eagle's medium supplemented with $10 \%$ fetal bovine serum (FBS) and maintained in $5 \% \mathrm{CO}_{2} / 95 \%$ air at $37{ }^{\circ} \mathrm{C}$. Hypoxia conditions were achieved in the tightly sealed hypoxia chambers by repeated evacuation and filling of $5 \% \mathrm{O}_{2} / 1 \% \mathrm{CO}_{2} / 94 \%$ $\mathrm{N}_{2}$ at $37^{\circ} \mathrm{C}$.

To examine the hypoxia-induced expression of CD151, H9C2 cells were cultured in 6-well plates to $70 \%-90 \%$ confluence and then transfected with pAAV-HRE-CD151, pAAVCD151, or pAAV-GFP using the FuGENE HD transfection reagent (Roche, MA, Germany). Non-transfected H9C2 cells were included as a control. At $48 \mathrm{~h}$ after the transfection, the infected cells were split into two parts: one part was cultured under normoxic conditions (95\% air, 5\% $\mathrm{CO}_{2}$ ) and the other part was cultured under hypoxic conditions $\left(94 \% \mathrm{~N}_{2}, 5 \% \mathrm{O}_{2}\right.$, and $\left.1 \% \mathrm{CO}_{2}\right)$ in serum-free medium for $16 \mathrm{~h}$. The individual experiments were repeated $(n=6)$.

\section{Ischemic heart model and injection of the plasmids}

Adult male Sprague-Dawley Rats (Animal Use and Care Center, Tongji Medical College, Wuhan, China) with weights of 200-250 g underwent a coronary artery ligation surgery. Under the anesthesia of pentobarbital $(60 \mathrm{mg} / \mathrm{kg}$, intraperitoneally), acute myocardial infarction (AMI) was induced by ligation of the left anterior descending coronary artery. Briefly, after intubation of the trachea, an incision was made in the skin overlying the 4 th intercostal space, with the overlying muscles separated and kept aside. The animals were placed under positive-pressure ventilation (frequency 65-70/ min, tidal volume $3 \mathrm{~mL}$ ), and the thoracic cavity was opened by cutting the intercostal muscles. The heart was carefully pushed to the left, and a 6-0 silk suture was looped under the left descending coronary artery near the origin of the pulmonary artery. Proper occlusion of the coronary artery resulted in an extensive transmural infarction comprising a major part of the left ventricle (LV) free wall, with small variations in size. Coronary occlusion was confirmed by the raised segment (ST) stages on the electrocardiogram and ventricular arrhythmias within the first 20-30 min after the occlusion. Twentyfour survived rats were randomly divided into four groups one day after the surgery. The rats in the control group $(n=6)$ received a single dose of $1 \mathrm{~mL}$ saline solution by the sublingual vein, whereas the rats in the treatment groups $(n=6$ per group) were injected through the same route with a single dose of $1 \mathrm{~mL}$ saline solution containing $200 \mu \mathrm{g}$ of pAAV-GFP, pAAV-CD151, or pAAV-HRE-CD151 plasmids ${ }^{[21,22]}$. The animal protocols used were in compliance with the Guide for the Care and Use of Laboratory Animals and were approved by the Chinese Academy of Sciences.

\section{Western blot analysis}

Cardiac myoblasts were scraped off the plates and lysed in RIPA buffer ( $50 \mathrm{mmol} / \mathrm{L}$ Tris- $\mathrm{HCl}$ (pH 8.0), $150 \mathrm{mmol} / \mathrm{L} \mathrm{NaCl}$, $1 \%$ Nonidet-P40, $0.5 \%$ deoxycholic acid and $0.1 \%$ SDS) and centrifuged at $14000 \times \mathrm{g}$ at $4^{\circ} \mathrm{C}$ for $30 \mathrm{~min}$. Tissues from the infarcted heart areas were dissected. The tissues were homogenized in $500 \mu \mathrm{L}$ of $25 \mathrm{mmol} / \mathrm{L}$ Tris- $\mathrm{HCl}(\mathrm{pH}$ 7.4) containing $1 \%$ Triton X-100, 0.1\% SDS, 2 mmol/L EDTA, and 1\% protease inhibitor and centrifuged at $14000 \times g$ at $4^{\circ} \mathrm{C}$ for $30 \mathrm{~min}$. The protein concentration was measured by the Bradford method with bovine serum albumin as the standard. The cell and tissue lysates ( $50 \mu \mathrm{g}$ protein) were separated in SDS-PAGE, electrically transferred to polyvinyl difluoride membranes, and probed with antibodies against CD151 (Abcam, CA, UK) and $\beta$-actin (Sigma-Aldrich, MO, USA), followed by incubation with the horseradish peroxidase-conjugated 2nd antibody and chemiluminescence detection. The intensities of the protein bands were quantified by densitometry. 


\section{Real-time quantitative PCR}

Tissue samples from the infarcted heart areas were homogenized in TRIZOL solution (Invitrogen, CA, USA) and RNA was extracted from the tissue following the manufacturer's instruction. CD151 mRNA in the heart tissue was detected by real-time quantitative PCR. One microgram of total RNA was reverse-transcribed in a $20-\mu \mathrm{L}$ reaction mixture containing 4 $\mu \mathrm{L} 5 \times$ PrimeScript Buffer, $1 \mu \mathrm{L}$ Primescript RT Enzyme Mix I, $1 \mu \mathrm{L}$ Oligo dT Primer (50 $\mu \mathrm{mol} / \mathrm{L}), 1 \mu \mathrm{L}$ Random 6 mers (100 $\mu \mathrm{mol} / \mathrm{L}$ ), and $9 \mu \mathrm{L}$ RNAse-free $\mathrm{H}_{2} \mathrm{O}$ (TaKaRa, Dalian, China). The mixture was incubated at $37^{\circ} \mathrm{C}$ for $15 \mathrm{~min}$ and $85^{\circ} \mathrm{C}$ for $5 \mathrm{~s}$. Then, real-time PCR was performed in an Mx3000P system (Stratagene, CA, USA) using the SYBR ${ }^{\circledR}$ Premix Ex Taq $^{\mathrm{TM}}$ (TaKaRa, Dalian, China) and $2 \mu \mathrm{L}$ of cDNA was amplified in a $25-\mu \mathrm{L}$ reaction mixture containing $12.5 \mu \mathrm{L}$ of the SYBR Premix Ex Taq, $0.5 \mu \mathrm{L}$ of the forward primer $(10 \mu \mathrm{mol} / \mathrm{L})$, $0.5 \mu \mathrm{L}$ of the reverse primers $(10 \mu \mathrm{mol} / \mathrm{L}), 0.5 \mu \mathrm{L}$ of the $\mathrm{ROX}$ Reference Dye, and $9 \mu \mathrm{L}$ of $\mathrm{dH}_{2} \mathrm{O}$. Amplifications were as follows: $95^{\circ} \mathrm{C}$ for $30 \mathrm{~s}$, followed by 40 cycles of $95^{\circ} \mathrm{C}$ for $5 \mathrm{~s}$, $58{ }^{\circ} \mathrm{C}$ for $20 \mathrm{~s}$, and $72{ }^{\circ} \mathrm{C}$ for $15 \mathrm{~s}$. The forward and reverse primers for CD151 are 5'-TGGGTGAGTTCAACGAGAAG-3' and 5'-AGCCAGAAGCAGCAATTGTA-3', respectively, and those for $\beta$-actin are $5^{\prime}$-CCCATCTATGAGGGTTACGC-3' and 5'-TTTAATGTCACGCACGATTTC-3', respectively. The reverse-transcribed cDNA samples were amplified, and cycle threshold $(\mathrm{Ct})$ values were determined. The mRNA levels of CD151 were normalized to the mRNA levels of the housekeeping gene $\beta$-actin. The comparative $\mathrm{Ct}$ method $\left(2^{-\Delta \Delta \mathrm{Ct}}\right)^{[23]}$ was used to analyze the differences in the level of CD151 mRNA between each group.

\section{Immunohistochemistry analysis and data acquisition}

Heart tissue specimens were taken from the infarcted regions in the left ventricle 4 weeks after the plasmid administration, fixed in $10 \%$ formalin, embedded in paraffin, and cut into $4-\mu \mathrm{m}$ thick sections. Some sections were stained with hematoxylin and eosin (H-E), and others were used for immunohistochemical staining with vWF (Santa Cruz, CA, USA) and SMa-actin (Sigma-Aldrich, MO, USA) antibodies for capillaries and arterioles, respectively. The densities of capillaries and arterioles were assessed according to the method previously described $^{[10]}$. Five regions that are rich in blood vessels were selected, and the vessels of each region that are within $400 \times$ microscopic field (for capillary) or $100 \times$ microscopic field (for arteriole) were counted by two blinded investigators without knowledge of the group identity. The numbers of capillaries (vWF positive) and arterioles (SM a-actin positive) in each field were counted under ocular micrometers (Olympus, Tokyo, Japan), and a total of five high-powered fields (HPF) per region per heart were quantified.

\section{Statistical analysis}

The statistical comparisons of the data were performed with a one-way analysis of variance (ANOVA), followed by the Newman-Keuls test for unpaired data. The results were expressed as the mean \pm standard error of the mean (SEM). A probability value of less than $5 \%$ was considered statistically significant.

\section{Results}

\section{Construction of pAAV-HRE-CD151 plasmid}

To induce CD151 expression in a hypoxia-dependent manner, we generated a recombinant pAAV-HRE-CD151 vector by placing the 68-bp HRE sequence from the human ENO gene between the Mlu I and BamH I restriction sites upstream of the cytomegalovirus promotor in the pAAV-CD151 plasmid. The correct insertion and intactness of the HRE sequence was confirmed by the nucleotide sequencing of the pAAV-HRE-CD151 vector (Figure 1).
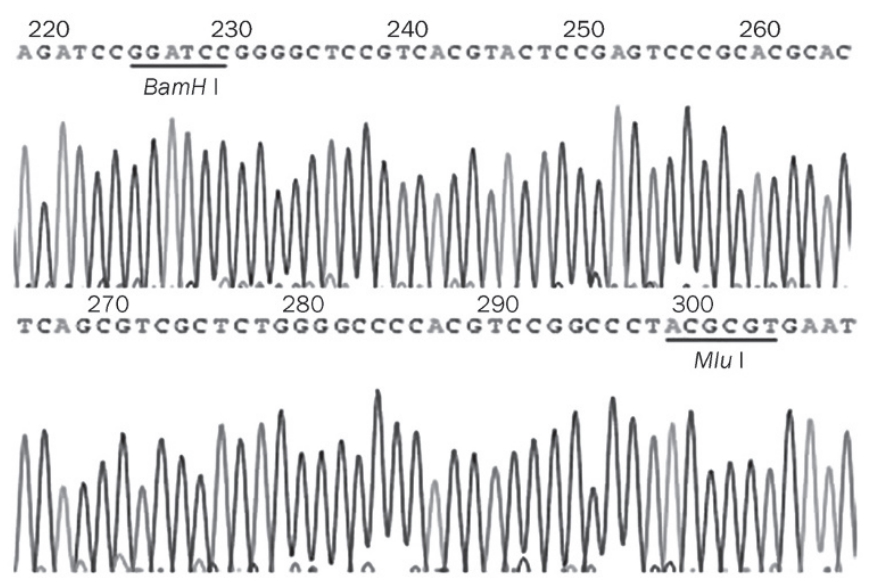

Figure 1. Identification of pAAV-HRE-CD151 by nucleotide sequencing. The sequence between the BamH I and Mlu I restriction sites is the HRE reverse complementary sequence (68 bp).

\section{HRE-induced in vitro CD151 expression in cardiac myoblasts}

To determine if the HRE enhancer can conditionally induce AAV-mediated CD151 gene expression under hypoxic conditions, we expressed the plasmids of pAAV-HRE-CD151, pAAV-CD151, and pAAV-GFP in H9C2 cardiac myoblasts. Under the hypoxic conditions, CD151 protein expression was significantly increased in the pAAV-HRE-CD151 group compared to the pAAV-CD151, pAAV-GFP, and non-transfected cardiac myoblast groups $(P<0.01)$. Under the normoxic conditions, CD151 protein expression was increased significantly in the pAAV-HRE-CD151 group compared to the pAAV-GFP and non-transfected cardiac myoblast groups $(P<0.01)$; however, there was no significant difference in CD151 expression between the pAAV-HRE-CD151 and pAAV-CD151 groups. These results indicated that the HRE of ENO enhanced the AAV vector-mediated CD151 expression in cultured cardiac myoblasts under the hypoxic condition (Figure 2). In all experiments, an equal number of cells were lysed from each group to level the total protein loading, and actin expression was used to normalize the CD151 expression in each group. 
A

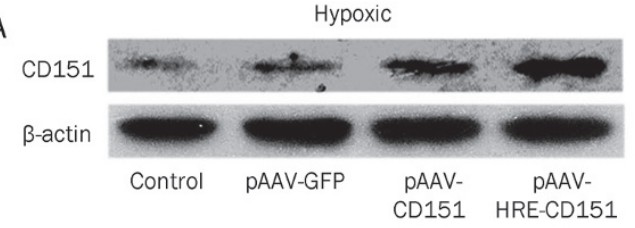

B

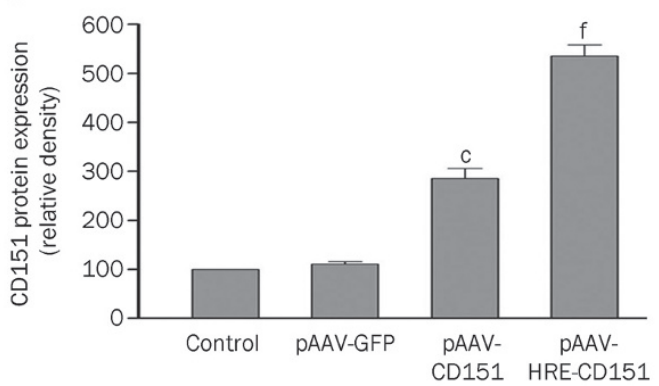

C
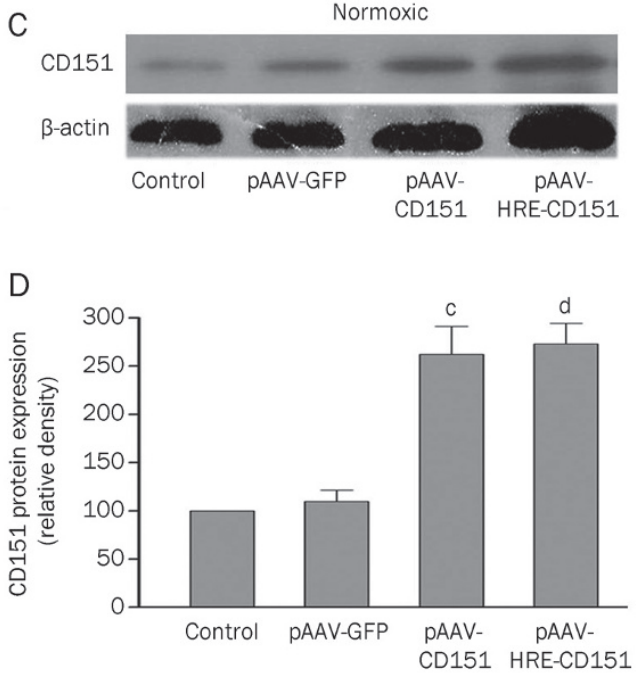

Figure 2. Hypoxic induction of CD151 expression in H9C2 cells after CD151-expressing vector transfection. (A) Western blot analysis of CD151 expression in hypoxic conditions. $\beta$-actin was used as an internal control. (B) Quantitative analysis of CD151 protein expression. The mean density of CD151 in the control group was defined as 100\%. Data are presented as means \pm SEM ( $n=4-6$ per group). ${ }^{c} P<0.01$ vs control and pAAV-GFP groups. ${ }^{f} P<0.01$ vs the pAAV-CD151 group. (C) Western blot analysis of CD151 expression in normoxic conditions. $\beta$-actin was used as an internal control. (D) Quantitative analysis of CD151 protein expression. The mean density of CD151 in the control group was defined as 100\%. Data are presented as means \pm SEM ( $n=4-6$ per group). ${ }^{c} P<0.01$ vs control and pAAV-GFP groups, ${ }^{\mathrm{d}} P>0.05$ vs the pAAV-CD151 group.

\section{Induction of CD151 expression by HRE in the ischemic myo-} cardium

The ENO HRE-driven in vivo expression of CD151 was assessed by intravenously injecting pAAV-GFP, pAAVCD151, and pAAV-HRE-CD151 vectors into the ischemic rat heart. CD151 expression was analyzed at the mRNA level using real time PCR. The CD151 level in the ischemic hearts of the pAAV-HRE-CD151 group was markedly higher than that in the saline control and pAAV-GFP groups $(P<0.01)$ (Figure 3). In the same model, the CD151 level in the pAAVHRE-CD151 group was higher than that in the pAAV-CD151 group $(P<0.01)$. Consistent with the results in vitro, ENO HRE significantly enhances CD151 expression in the ischemic myocardium in vivo.

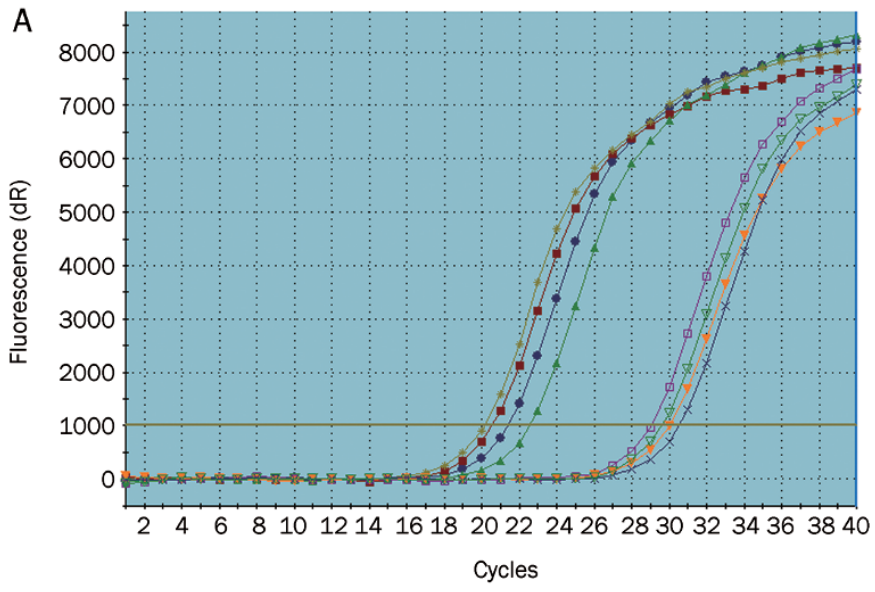

B

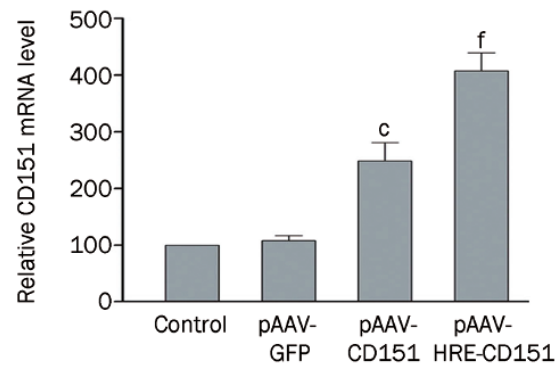

Figure 3. Induction of CD151 expression by HRE in the ischemic myocardium after CD151 gene delivery. Four weeks after coronary artery ligation, samples were collected from the same heart regions. (A) Realtime PCR amplification plots of CD151 and $\beta$-actin. (B) The mRNA levels for $\mathrm{CD} 151$ and $\beta$-actin after gene delivery. $\beta$-Actin was used as an internal control. In each group, the CD151 mRNA level was normalized to the $\beta$-actin mRNA level. The data are presented as the ratio of the treated group to the saline control group, which was defined as $100 \%$. The results are presented as means \pm SEM ( $n=4-5$ per group); ${ }^{c} P<0.01$ between the pAAV-CD151 group and the saline control and pAAV-GFP groups. ${ }^{f} P<0.01$ between the pAAV-HRE-CD151 group and the saline control, pAAV-GFP, or pAAV-CD151 groups.

Western blot analysis demonstrated that the levels of human CD151 proteins extracted from ischemic myocardium were increased significantly in the pAAV-CD151 and pAAV-HRECD151 groups compared with the saline control and pAAVGFP groups $(P<0.01$, Figure 4$)$. In contrast, the expression of CD151 proteins in the pAAV-HRE-CD151 group was higher than that in the pAAV-CD151 group $(P<0.01)$. There was no significant difference in the level of CD151 proteins between the saline control and pAAV-GFP groups $(P>0.05)$. These 
A

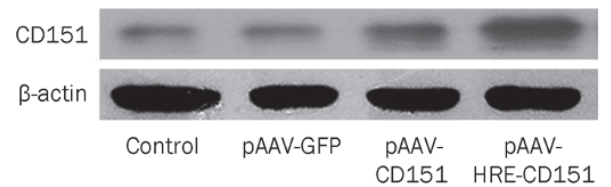

B

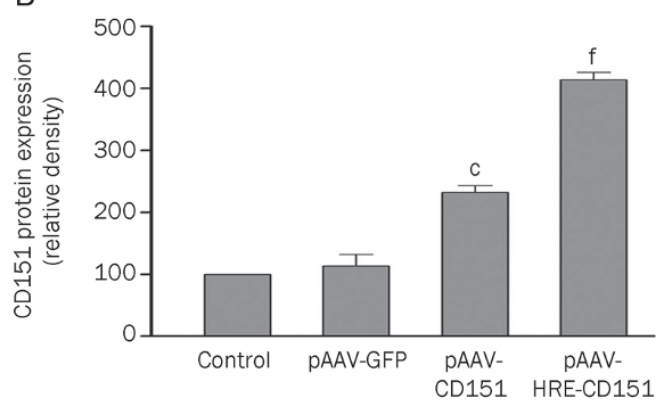

Figure 4. Enhancement of CD151 expression by HRE in the ischemic myocardium after CD151 gene delivery. Four weeks after coronary artery ligation, tissue samples were collected from the same heart regions. (A) Western blot analysis for $\mathrm{CD} 151$ and $\beta$-actin. $\beta$-Actin serves as an internal protein loading control. (B) Quantification of CD151. The density of the CD151 band in the saline control group was arbitrarily defined as 100 units, and the densities in other groups are the relative levels to 100 units. Data are presented as means \pm SEM $(n=6-8) .{ }^{c} P<0.01$ between the pAAV-CD151 group and the saline control and pAAV-GFP groups. ${ }^{f} P<0.01$ between the pAAV-HRE-CD151 group and the saline control, pAAV-GFP, or pAAV-CD151 groups.

results indicate that AAV-mediated CD151 gene delivery promotes CD151 protein expression in myocardial tissue and that ENO HRE can induce higher CD151 expression in the ischemic myocardium in vivo.

\section{Analysis of arteriole and capillary density}

The formation of capillaries and arterioles was evaluated by vWF and SM a-actin staining, respectively, at 4 weeks after the plasmid injections. Higher microvessel densities were found in the pAAV-HRE-CD151 and pAAV-CD151 groups and less neovascularization was found in the saline control and pAAVGFP groups (Figure 5). There were no significant differences in the numbers of microvessels $(P>0.05)$ between the saline control and pAAV-GFP groups. In contrast, the capillary and arteriole densities in the pAAV-HRE-CD151 group were markedly higher than that in the pAAV-CD151 group $(P<0.01)$. These findings indicate that the ENO HRE-induced higher CD151 expression is correlated with more neovascularization in the ischemic myocardium. This further supports our earlier observation that CD151 gene delivery increases the formation of capillaries and arterioles.

\section{Discussion}

Despite the success of bypass surgery and angioplasty, many patients have a limited opportunity to accomplish revascularization in the ischemia myocardium because of diffused coronary artherosclerosis, occluded bypass grafts, or excessive risk of surgery. Hence, ischemic heart disease remains the leading cause of morbidity and mortality in the world. Therapeutic angiogenesis, using angiogenic growth factors or cytokines to stimulate collateral blood vessel formation, has been tested as an alternative treatment $t^{[14,24,25]}$. The pro-angiogenesis factors that have been investigated include CD151, $\operatorname{VEGFs}^{[1,7]}$, $\mathrm{FGFs}^{[25]}$, and angiopoietins ${ }^{[26]}$. As a member of the tetraspanin family, CD151 plays a role in regulating endothelial cell (EC) motility and angiogenesis in vitro ${ }^{[4,27]}$. A recent study demonstrates that the mouse lung ECs (MLECs) from CD151-null mice display marked reduction in the angiogenesis-related endothelial events including migration, spreading, invasion, Matrigel contraction, tube and cable formation, and spheroid sprouting ${ }^{[28]}$. Conversely, overexpression of CD151 in human umbilical vein ECs enhances cell proliferation, migration, and capillary tube formation on Matrigel ${ }^{[29]}$. We have reported that CD151 gene delivery increases the number of microvessels in a rat myocardial ischemia model and an ischemic rat hindlimb mode ${ }^{[7,8]}$. Further studies have underlined that CD151 gene delivery promotes angiogenesis in a pig myocardial ischemia model and demonstrated that CD151-induced neovascularization effectively enhances the myocardial perfusion and markedly ameliorates the regional myocardial dysfunction based on ${ }^{13} \mathrm{~N}-\mathrm{NH}_{3}$ PET imaging and echocardiography ${ }^{[9,10]}$. All these observations strongly suggest that CD151 can be useful for gene therapy to target myocardial ischemia by promoting angiogenesis.

The adeno-associated virus (AAV) vector belongs to the nonpathogenic member of the parvovirus family. It has several advantages over other viral vectors such as low immunogenicity, a long-term expression of transgene, and an ability to infect both dividing and nondividing cells ${ }^{[30]}$. Our previous studies have also found that AAV is an efficient vector for the in vivo transfer and sustained expression of the CD151 gene in the myocardium. AAV-mediated CD151 gene transfer provides heart with effective and long-lasting protection from acute myocardial infarction-induced injuries.

A potential problem associated with exogenous gene therapy is that different dosages and durations of the exogenous gene stimulation may yield different results. A relatively low level of the angiogenic factor in the myocardium is insufficient to induce angiogenesis, because transient exposure to the exogenous genes in humans was insufficient to trigger and maintain a therapeutically meaningful angiogenic response in clinical trials, especially when patients also had an extensive atherosclerotic disease $\mathrm{e}^{[31]}$. The administration or expression of angiogenic factors for the short term and/or at low levels either could not stimulate myocardial angiogenesis in initial clinical trials and induced only a short-lived angiogenic response ${ }^{[32]}$ or led to nonfunctional, hypo-perfused capillaries that regress when the levels of angiogenic factors drop ${ }^{[32]}$. For the treatment of ischemic heart disease, angiogenic therapy is aimed at stimulating functional and sustainable new blood vessels. However, an excessively high-level expression of the angiogenic factor in vivo may result in side effects in nonischemic sites such as excessive angiogenesis, which will lead 
A
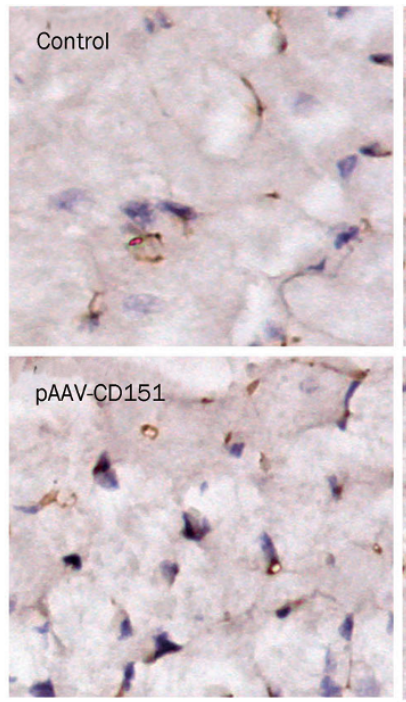
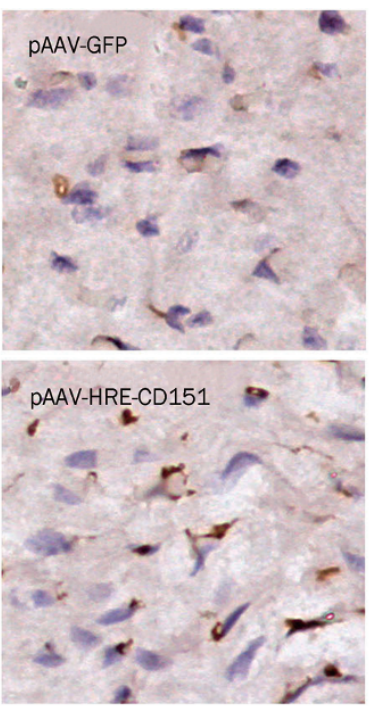

C
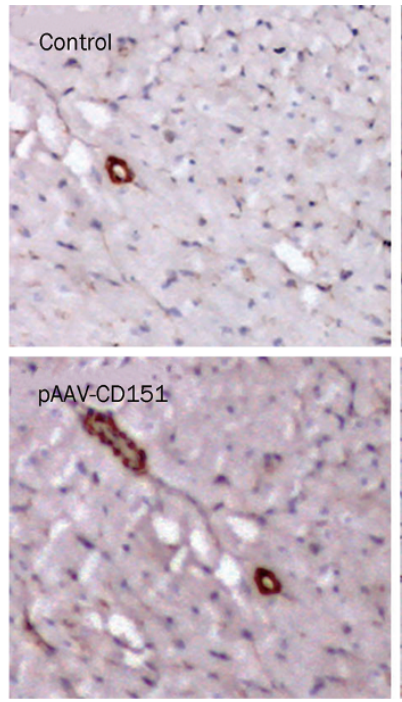
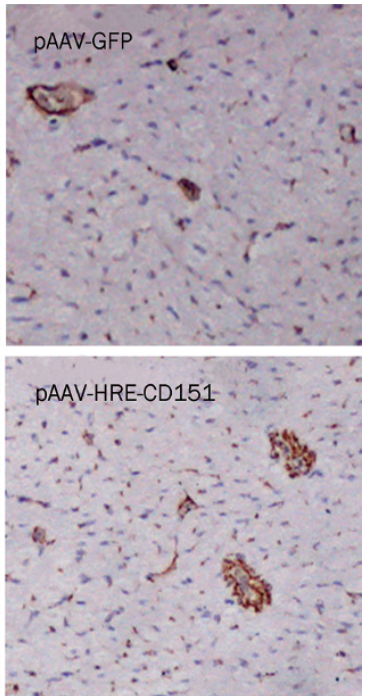

B

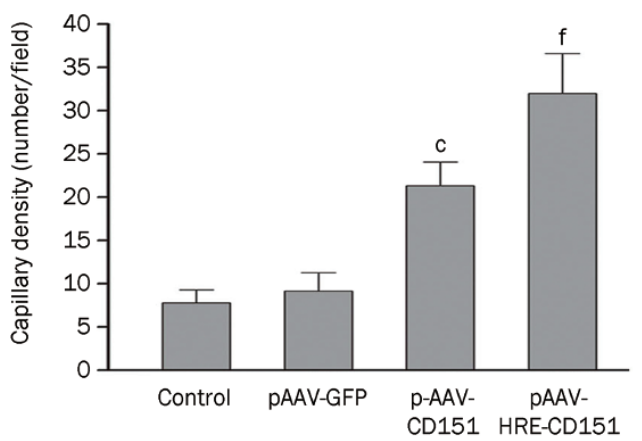

D

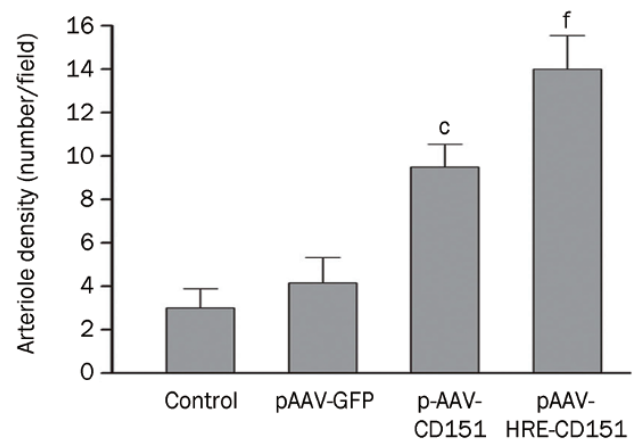

Figure 5. Overexpression of CD151 increases the densities of capillaries and arterioles. (A) Immunohistochemical staining of capillaries with antibody to von Willebrand factor (VWF). The ECs are stained in brown. (B) Quantification of the density of myocardial capillaries. (C) Immunohistochemical staining of arterioles with antibody to SM $\alpha$-actin. The smooth muscle cells are indicated in brown. (D) Quantification of the density of myocardial arterioles. Data are projected as means \pm SEM ( $n=4-6$ per group). ${ }^{\circ} P<0.01$ between the pAAV-CD151 group and the saline control and pAAV-GFP groups. ${ }^{f} P<0.01$ between the pAAV-HRE-CD151 group and the saline control, pAAV-GFP, or pAAV-CD151 groups.

to adverse consequences in the retina, synovium, and other $\operatorname{areas}^{[12,33]}$. Thus, long-lasting and reasonably high levels of exogenous gene stimulation are needed for clinical success. More importantly, it is crucial to increase the exogenous gene expression only in the ischemic myocardium without significantly affecting the global level of this gene in the body.

One ideal mechanism to regulate the exogenous gene expression in the ischemic heart is to allow the expression of this gene in response to hypoxia. Earlier studies demonstrated that an increased level of HIF-1a in the ischemic myocardium was found as early as 2 days after the coronary artery occlusion and lasted until 2 weeks later ${ }^{[14]}$. Therefore, the HIF-1a/ HRE is an ideal regulatory system to be used for controlling exogenous gene expression in the ischemic myocardium. To maintain a higher level of CD151 expression in the ischemic regions and meanwhile reduce the side-effects, we chose to inject a lower level of the CD151 gene and make use of HRE to induce higher CD151 gene expression in the hypoxic area.
Consequently, the angiogenesis induced by uncontrolled and persistently expressed exogenous gene can be avoided by HRE-controlled CD151 expression. We chose to use ENO HRE in our study because Phillips et al showed that HRE from ENO yielded the best induction of gene expression under hypoxic conditions ${ }^{[20]}$. CD151 expression under the control of a HRE enhancer and CMV promoter exhibited marked upregulation under hypoxic conditions. This upregulation is likely mediated by HIF-1a in cardiomyocytes because H9C2 cells express HIF-1a in hypoxia ${ }^{[14]}$. In accordance with higher CD151 expression, the formation of capillaries and arterioles in the ischemic myocardium was also elevated under the HRE enhancer. These findings together suggest that hypoxia enhances CD151 expression in the ischemic myocardium in an HRE-dependent manner and that higher CD151 gene expression in turn results in increased neovascularization.

In conclusion, we have demonstrated that ENO HRE enhances the AAV vector-mediated CD151 gene expression in 
cultured cardiomyocytes in vitro and ischemic rat myocardium in vivo. These results further demonstrate that the HIF-1/HRE axis is a useful system for controlling CD151 expression in the treatment of ischemic heart disease and potentiates the efficacy of CD151-based gene therapy.

\section{Acknowledgements}

This work was supported by a grant from the National Natural Science of China (№ 30670856).

\section{Author contribution}

Xiao-lin HUANG and Zheng-xiang LIU designed the study and handled funding; Quan WEI, Jing-yang LIN, and Yu-jie FEI performed the research, analyzed the data and drafted the manuscript; Xin A ZHANG contributed the reagents and analytical tools and reviewed and revised the manuscript.

\section{References}

$1 \mathrm{Su} \mathrm{H}$, Lu R, Kan YW. Adeno-associated viral vector-mediated vascular endothelial growth factor gene transfer induces neovascular formation in ischemic heart. Proc Natl Acad Sci USA 2000; 97: 13801-6.

2 Fitter S, Tetaz TJ, Berndt MC, Ashman LK. Molecular cloning of cDNA encoding a novel platelet-endothelial cell tetra-span antigen, PETA-3. Blood 1995; 86: 1348-55.

3 Hasegawa H, Utsunomiya Y, Kishimoto K, Yanagisawa K, Fujita S. SFA1, a novel cellular gene induced by human T-cell leukemia virus type 1 , is a member of the transmembrane 4 superfamily. J Virol 1996; 70 : 3258-63.

4 Sincock PM, Fitter S, Parton RG, Berndt MC, Gamble JR, Ashman LK. PETA-3/CD151, a member of the transmembrane 4 superfamily, is localised to the plasma membrane and endocytic system of endothelial cells, associates with multiple integrins and modulates cell function. J Cell Sci 1999; 112: 833-44.

5 Zhang XA, Bontrager AL, Hemler ME. Transmembrane-4 superfamily proteins associate with activated protein kinase $C(P K C)$ and link PKC to specific beta(1) integrins. J Biol Chem 2001; 276: 25005-13.

6 Sincock PM, Mayrhofer G, Ashman LK. Localization of the transmembrane 4 superfamily (TM4SF) member PETA-3 (CD151) in normal human tissues: comparison with CD9, CD63, and alpha5beta1 integrin. J Histochem Cytochem 1997; 45: 515-25.

7 Lan RF, Liu ZX, Liu XC, Song YE, Wang DW. CD151 promotes neovascularization and improves blood perfusion in a rat hind-limb ischemia model. J Endovasc Ther 2005; 12: 469-78.

8 Zheng Z, Liu Z. CD151 gene delivery activates PI3K/Akt pathway and promotes neovascularization after myocardial infarction in rats. Mol Med 2006; 12: 214-20.

9 Zuo HJ, Liu ZX, Liu XC, Yang J, Liu T, Wen S, et al. Assessment of myocardial blood perfusion improved by CD151 in a pig myocardial infarction model. Acta Pharmacol Sin 2009; 30: 70-7.

10 Zuo H, Liu Z, Liu X, Yang J, Liu T, Wen S, et al. CD151 gene delivery after myocardial infarction promotes functional neovascularization and activates FAK signaling. Mol Med 2009; 15: 307-15.

11 Schwarz ER, Speakman MT, Patterson M, Hale SS, Isner JM, Kedes $\mathrm{LH}$, et al. Evaluation of the effects of intramyocardial injection of DNA expressing vascular endothelial growth factor (VEGF) in a myocardial infarction model in the rat - angiogenesis and angioma formation. J Am Coll Cardiol 2000; 35: 1323-30.

12 Lee RJ, Springer ML, Blanco-Bose WE, Shaw R, Ursell PC, Blau HM. VEGF gene delivery to myocardium: deleterious effects of unregulated expression. Circulation 2000; 102: 898-901.

$13 \mathrm{Su} \mathrm{H}$, Kan YW. Adeno-associated viral vector-delivered hypoxiainducible gene expression in ischemic hearts. Methods Mol Biol 2007; 366: 331-42.

$14 \mathrm{Su} \mathrm{H}$, Arakawa-Hoyt J, Kan YW. Adeno-associated viral vectormediated hypoxia response element-regulated gene expression in mouse ischemic heart model. Proc Natl Acad Sci USA 2002; 99: 9480-5.

15 Semenza GL, Jiang BH, Leung SW, Passantino R, Concordet JP, Maire $\mathrm{P}$, et al. Hypoxia response elements in the aldolase $\mathrm{A}$, enolase 1 , and lactate dehydrogenase A gene promoters contain essential binding sites for hypoxia-inducible factor 1 . J Biol Chem 1996; 271: 3252937.

16 Gupta M, Mungai PT, Goldwasser E. A new transacting factor that modulates hypoxia-induced expression of the erythropoietin gene. Blood 2000; 96: 491-7.

17 Koshikawa N, Takenaga K, Tagawa M, Sakiyama S. Therapeutic efficacy of the suicide gene driven by the promoter of vascular endothelial growth factor gene against hypoxic tumor cells. Cancer Res 2000; 60: 2936-41.

18 Ruan H, Su H, Hu L, Lamborn KR, Kan YW, Deen DF. A hypoxiaregulated adeno-associated virus vector for cancer-specific gene therapy. Neoplasia 2001; 3: 255-63.

19 Lan R, Liu Z, Song Y, Zhang X. Effects of rAAV-CD151 and rAAVantiCD151 on the migration of human tongue squamous carcinoma cell line Tca8113. J Huazhong Univ Sci Tech Med Sci 2004; 24: 556-9.

20 Phillips MI, Tang Y, Schmidt-Ott K, Qian K, Kagiyama S. Vigilant vector: heart-specific promoter in an adeno-associated virus vector for cardioprotection. Hypertension 2002; 39: 651-5.

21 Xia JL, Dai C, Michalopoulos GK, Liu Y. Hepatocyte growth factor attenuates liver fibrosis induced by bile duct ligation. Am J Pathol 2006; 168: 1500-12.

22 Deng X, Szabo S, Khomenko T, Jadus MR, Yoshida M. Gene therapy with adenoviral plasmids or naked DNA of vascular endothelial growth factor and platelet-derived growth factor accelerates healing of duodenal ulcer in rats. J Pharmacol Exp Ther 2004; 311: 982-8.

23 Schmittgen TD, Livak KJ. Analyzing real-time PCR data by the comparative C(T) method. Nat Protoc 2008; 3: 1101-8.

24 Yla-Herttuala S, Martin JF. Cardiovascular gene therapy. Lancet 2000; 355: 213-22.

25 Simons M, Annex BH, Laham RJ, Kleiman N, Henry T, Dauerman H, et al. Pharmacological treatment of coronary artery disease with recombinant fibroblast growth factor-2: double-blind, randomized, controlled clinical trial. Circulation 2002; 105: 788-93.

26 Sung HK, Kim YW, Choi SJ, Kim JY, Jeune KH, Won KC, et al. COMPangiopoietin-1 enhances skeletal muscle blood flow and insulin sensitivity in mice. Am J Physiol Endocrinol Metab 2009; 297: E402409.

27 Zhang XA, Kazarov AR, Yang X, Bontrager AL, Stipp CS, Hemler ME. Function of the tetraspanin CD151-alpha6beta1 integrin complex during cellular morphogenesis. Mol Biol Cell 2002; 13: 1-11.

28 Takeda Y, Kazarov AR, Butterfield CE, Hopkins BD, Benjamin LE, Kaipainen A, et al. Deletion of tetraspanin Cd151 results in decreased pathologic angiogenesis in vivo and in vitro. Blood 2007; 109: 1524-32.

29 Zheng ZZ, Liu ZX. Activation of the phosphatidylinositol 3-kinase/ protein kinase Akt pathway mediates CD151-induced endothelial cell proliferation and cell migration. Int J Biochem Cell Biol 2007; 39: 340-8.

30 Shen F, Su H, Fan Y, Chen Y, Zhu Y, Liu W, et al. Adeno-associated 
viral-vector-mediated hypoxia-inducible vascular endothelial growth factor gene expression attenuates ischemic brain injury after focal cerebral ischemia in mice. Stroke 2006; 37: 2601-6.

31 Ferrara N, Alitalo K. Clinical applications of angiogenic growth factors and their inhibitors. Nat Med 1999; 5: 1359-64.

32 Pettersson A, Nagy JA, Brown LF, Sundberg C, Morgan E, Jungles S, et al. Heterogeneity of the angiogenic response induced in different normal adult tissues by vascular permeability factor/vascular endothelial growth factor. Lab Invest 2000; 80: 99-115.

33 Shen F, Fan Y, Su H, Zhu Y, Chen Y, Liu W, et al. Adeno-associated viral vector-mediated hypoxia-regulated VEGF gene transfer promotes angiogenesis following focal cerebral ischemia in mice. Gene Ther 2008; 15: 30-9. 